\title{
Regional Integration and Development in Africa: Between the Rock and a Hard Place
}

\author{
Friday Aworawo \\ Department of History and Strategic Studies \\ University of Lagos, Nigeria \\ faworawo@unilag.edu.ng \\ DOI: https://doi.org/10.32890/jis2016.12.2
}

\begin{abstract}
Since independence in the late 1950s, and in the early 1960s, regional integration in Africa has been identified as an important strategy for the acceleration of development in the continent. The reality of the Post-Cold War international economic world order also stimulates the intensification and fine-tuning of existing regional arrangements leading to the establishment of a supra-national organization and capacity building institutions to address the problems of underdevelopment in Africa. As a consequence, numerous integration groupings have been reorganized and created but their achievements have largely been modest due to inappropriate integration approaches. It is against this background that this article examines the interlocking nexus between regional integration and development in Africa, and maintains that Africans need to adjust their orientation as well as take a major shift towards economic complementarity among member states of integration blocs for the actualization of laudable development. It concludes that inward looking and the involvement of all Africans in the regional integration processes would be the best approach for regional integration to foster development.
\end{abstract}

Keywords: Integration, regional organization, development, Africa.

\section{Introduction}

Since independence, states in Africa have been involved in regional integration as a strategy for solving their developmental challenges. This is because regional integration has been identified as a pivotal factor in the promotion of economic development. As a result, some numbers of regional integration arrangements have been established in the last forty years to promote regional cooperation accompanied by continental development. Accordingly, a series of integration initiatives aimed at addressing developmental problems in the continent has accounted for the proliferation of regional organizations. And against the background of Africa's economic recession in the late 1960s, regional integration was conceived as an inevitable mechanism toward economic recovery. Some of the regional integration organizations formed to enhance Africa's development, but not limited to the following, include: the East African Community (EAC), the Economic Community of West 
African States (ECOWAS), the Southern African Development Community (SADC), and the African Union (AU) just to mention a few.

In fact, before independence in the 1960s, the desire for integration was a prominent discourse among political leaders in Africa. It should be recalled that among the pioneering moves, the Nkrumah-led All African People Conference in 1958, canvassed for continental integration as a strategy to solve the numerous challenges bedeviling Africa at the dawn of political independence (Osuntokun, 2006; Agubuzu, 2004). During the same year, the United Nations' Economic and Social Council, on 29 April 1958, with Resolution 671A (xxv) established the Economic Commission for Africa (ECA) (Adeogun, 2013). Among other things, the ECA was saddled with the responsibility of promoting Africa's economic development through integration. Therefore, integration was pinpointed as a viable framework that would bring numerous benefits to Africa as well as enabling the continent to overcome the heterogeneous division, to which Africa had been divided. Thus, the establishment of the defunct Organization of Africa Unity (OAU) - now African Union (AU) - which emerged in May 1963 as a compromise in this direction; shortly after the debate between the Monrovia and the Casablanca blocs under which most African political leaders were divided in the early 1960s (Falola, 1991).

Indeed the continental body emerged with a caveat that regional economic bodies would serve as forerunners to continental integration and development. It was against this understanding as well as the Post-Cold War international economic order that witnessed the emergence of large trading blocs such as the European Union, the North America Free Trade Area, the Association of South-East Asian Nations, just to mention a few, were created (Okonkwo, 2006). It was a development that made it pertinent for African states to form similar regional bodies that would give them the clout with other trading blocs in the international system and to overcome developmental problems.

The realization of the above, therefore, necessitated the emergence of not less than two regional organizations in West Africa, South Africa, East Africa and the North African sub regions of the continent. The details of all these are discussed after the analysis of the theoretical framework of the paper.

\section{Theoretical Framework}

There are many theories and perspectives on regional economic cooperation and integration. Most of the theories have provided us with fascinating debates and understanding of what is thought to be the best way of organizing integration blocs in such a way as to ensure their effectiveness and endurance. This is because the history of evolution and the formation of integration bodies or international organizations is replete with the rise and fall or collapse of international organizations.

Regarding the best way to effectively carry out integration and economic cooperation, the most prominent ideas since the end of the Second World War have revolved around the 
functionalism and the neo-functionalism theories of integration. This paper is encapsulated in the functionalism and the neo-functionalism theories. The functionalism theory was first developed by David Mitrany (1943), and is perhaps the most influential proponent of the perspective. In his book, A Working Peace System, and other additional works, Mitrany opined that the greatest impediment to integration is the unwillingness of countries to surrender their sovereignty to a supra-national body. Mitrany also contends that while technology is making the world smaller and drawing people nearer, politics has persisted in canalizing irrational divisiveness as experienced in most nations (Ogbeidi, 2003).

Therefore, according to Mitrany, high politics has hindered efforts to establish integration bodies whose decision would outweigh and be binding on member states. To overcome these challenges, Mitrany, submits that integration arrangements should begin with cooperation on social, culture, economic, sport, trade, commerce and scientific exchanges. The arrangement should be global not regional. And if all the member states benefit from the cooperation and integration of these issues without any major loss by any one of them, then, member states would enthusiastically support the integration arrangement. And when disagreement ensured in one issue areas, attention should be diverted to other issues.

Mitrany is perspective on regional integration through international organizations was taken to a higher level of refinement by integrationist scholars such as Ernest Haas, Phillip Schmitter (1970) and Joseph Nye (1968). Their perspectives came to be called neo-functionalism. As already noted, the neo-functionalism theory is a continuation or a reformation of functionalism. The principles of both theories are essentially the same in many respects though markedly differ in their conclusions. For instance, the neo-functionalists supported the original functionalists' argument that integration should begin with social, culture, economy, trade and commerce.

The neo-functionalists also provide us with different variables, which integration bodies must consider to be successful. These include the background condition of the integration countries, the prevailing environment after an integration arrangement and the general development as integration arrangement flourishes. The last variable is the mechanism for conflict resolution within the integration arrangement. Thus, the main difference between functionalism and neo-functionalism is that while the former lays more emphasis on global integration process, the latter emphasizes regional rather global integration.

Many scholars have criticized both the functionalism and the neo-functionalism theories. For example, some had argued that both theories are based on European settings, and many developing countries in Africa cannot meet some of the conditions stipulated for effective integration.

Not withstanding the aforementioned, however, is that functionalism and neo-functionalism have influenced economic integration arrangements in the world since the end of World War II. Of course, the most prominent and successful integration body is the European Union, which has ensured the transformation of the states of Europe of to the state of Europe. On 
the whole, both theories helped in analyzing the functioning of the regional integration arrangement in Africa, particularly on issues of cooperation and the unwillingness of the states in Africa to voluntarily give their powers to regional groupings.

\section{Regional Integration and Africa's Development}

Like most concepts in the humanities, social and management sciences, regional integration does not enjoy a universally acceptable definition as many scholars, experts and generalists have defined the concept based on their intellectual orientations. Kehinde (2014) for example defined regional integration as a global phenomenon of territorial groupings, which aimed at increasing interactions among component states as well as creating new forms of organizations that coexist with traditional forms of state-led institutions at the national level.

It may equally be defined as a process, which states enter into a regional agreement in order to enhance regional cooperation through regional organizations and rules (Aworawo, 2006). For Asante (2010) it is an association of states based upon location in a given geographical area for the safeguarding or promotion of the participant's interests by a treaty or other arrangements. It is also considered as a process by which states within a particular region increase their interaction with regard to economic, social, cultural, political and security issues (Ginkel, 2010). According to Karl Deutsch (1989) a strong advocate of regional integration, regional integration refers to cooperation among political entities leading to the formation of a new centre and the creation of a sense of identity and an integrated community. To Ernest Haas (1968) regional integration is a tendency towards the voluntary creation of larger political units, each of which self-consciously eschews the use of force in the relationship between the participating units.

A dispassionate appraisal of the above definitions reveals that regional integration involves turning hitherto units into a component of a coherent system, which would produce system properties that they separately lacked. It could also be argued that regional integration is a process by which the states involved begin to voluntarily give up certain sovereign powers and evolve new strategies for addressing common challenges.

Notwithstanding the differences in the definitions on what regional integration is expected to address, the interests of the states involved in such arrangements are the primary concern of any regional grouping. In specific terms, however, scholars have identified the following functions for any integration framework to fulfill:

- enable countries to enjoy economy on a large scale by the pooling together the resources;

- strengthen the regions' interaction with other regions of the world;

- strengthen of trade integration in the region of operation;

- contribute toward peace, conflict resolution and security in the region;

- create an appropriate enabling environment for private sector development; 
- develop infrastructure programmes in support of economic growth and regional integration;

- develop strong public sector institutions and good governance;

- reduce social exclusion and the development of an inclusive civil society;

- build environmental programmes at the regional level and

- turn hitherto separate political units into a coherent system(De lombaerde and Van, 2007).

As noted above, regional integration arrangements are expected to foster growth and development between and among the participating members. And in view of the development dichotomy between the developed and the developing countries of the world, regional integration are a necessity for the promotion of intra-trade relations in Africa in order to reduce the trade balance deficit, which currently exists between many African states and the advanced economies of the world.

\section{The Functioning Of Regional Groupings and Africa's Development Since The 1960s}

Since independence in the 1960s, and particularly after the formation of the defunct OAU (now AU) as a compromise to move Africa forward, regional integration or sub-regional arrangement has been seen in many respects, as agents for continental development. As a result, numerous sub-regional organizations were established to foster integration and enhance development in Africa. Accordingly, many regional integration frameworks had been created in Africa to achieve economic emancipation, and to address African underdevelopment challenges. Consequently, sub-regional organizations have proliferated in all the regions or sub-regions of Africa.

To be modest, there are over sixteen sub-regional groupings in Africa, with at least two in each sub-region of the continent. In North Africa, is the Union of Arab Megrebian Union (UMA) established in 1965, consisting of Algeria, Libya, Morocco and Tunisia (Aworawo, 2012). The region also hosts the Community of Sahel-Sahara States (CENSAD). The Southern Africa region hosts several integration blocs or groups such as the Rand Monetary Area founded in 1974, the Southern Africa Development Community (SADC) created in 1980 as well as the Common market for East and Southern Africa (COMESA) established in 2000. Other regional groups in the region include the Indian Ocean Commission (IOC), the Southern African Custom Union (SACU), and the intergovernmental Authority on Development (IGAD) (SADC, 2015).

Like other parts of Africa, the lure for regional integration as a mechanism to foster development equally necessitated the creation of a regional grouping in West Africa. Some of the regional framework to be found in the region are; the Economic Community of West African States (ECOWAS) founded in 1975, and the Mano River Union (MRU) created in 1974 (Adejo, 2010). 
Efforts have also been made in the quest for regional integration in Central Africa. The Economic Community of Central African states was formed in 1983 by the same countries that made up the Customs and Economic Union of Central African States. In fact, the Economic Community of the Great Lakes was founded in 1976 by what are today the Democratic Republic of Congo, Burundi and Angola. The East Africa sub-region also hosts the East African community established in 1967 (Bolariwa, 2014). It should be noted that the East African Community is the reappeared East African Common Market (EACM).

Based on the above, one can confidently say that there are numerous regional integration groupings all over Africa created for the promotion of economic integration, intra- and inter-trade relations as well as for accelerating Africa's development.

The aims and objectives of these regional groupings are similar in nature. Almost all the sub-regional organizations are formed to promote economic, social, political, cultural cooperation as well as to address issues of security and integration of member states. All these regional groupings equally have lofty ideas of raising the living standard of the peoples, maintain economic stability and foster peaceful relations among the member states with the hope of contributing to the of development of Africa. Indeed, all these aims and objectives emphasize a reasonable degree of optimism to accelerate the process leading to Africa's development. In the political sphere, the regional arrangements are charged with the responsibilities of giving African states an influence among the committee of nations, and oneness in relations with other trading blocs in the world. These regional integration groupings are also expected to promote unrestricted inter-states or member states relations and the free movement of goods and services between member countries.

An assessment of the general aims and the specific objectives of the various regional groupings at different sub-regions of Africa demonstrate the similarities, and overlap the objectives of the integration bodies in the continent. For example, ECOWAS' lofty aims of fostering development across West Africa are not markedly different from those of the SADC, just as the EAC equally emphasizes the promotion of regional trade and the unrestricted movement of people, goods and services as part of its specific objectives. To this end therefore, the next section of this paper examines the extent to which these subregion groupings have contributed to Africa's development against the backdrop of their lofty objectives.

\section{A Cost-Benefit Analysis of Regional Groupings and Africa's Development}

No doubt the proliferation of regional integration groupings in Africa demonstrates the willingness of each region of the continent's desire to promote economic cooperation and development between and among the African states.

However, despite the numerous initiatives formed to address developmental challenges in the continent, Africa is still characterized as one of the most underdeveloped continents 
on earth. Indeed many factors have been identified as fundamental to the slow or modest progress recorded by the regional organizations in Africa. Thus, the spirited efforts that necessitated the series of integration initiatives have not enabled the continent to overcome its division and underdevelopment.

For example, despite the formation of the Economic Commission for Africa (ECA), the Lagos Plan of Action (LPA) for the Economic Development of Africa coupled with the transformation to African Union, Africa is still experiencing misfortune (Bolariwa, 2014). As pointed out by Akinyeye (2008) even though world trade has witnessed a phenomenal growth in recent years, the African share of world trade remains abysmally low. ${ }^{20}$ It oscillates between 2 and $4 \%$ in successive years. Although, the continent's population of over 850 million is about $12 \%$ of the total world population, the Gross Domestic Product (GDP) of Africa is the lowest in the world. In fact, the GDP of Africa with an estimated population of over eight hundred and fifty million is just equal to that of Spain, a single country in Europe with an estimated population of about fifty million people (Akinyeye, 2008).

Thus, the continental bodies have not been able to realize their lofty objectives and functions. In fact, the African Union is only a Union by name and wish. This is because in spite of the establishment of multiple supra-national bodies, organs and commission by the Union, Africa is still in the situation of the early $19^{\text {th }}$ century Europe characterized by unending conflicts.

What about regional or sub-regional groupings across the continent? The newly disappeared and reappeared East African Community (EAC) was originally formed as a three-nation integration bloc between Tanzania, Kenya and Uganda. But by 1999, after a constructive debate, Burundi and Rwanda were admitted into the community in 2007. Indeed, the EAC has undergone some fundamental improvements covering social, economic and political areas of cooperation. And as observed by Kehinde (2014) the total intra-EAC trade and the organization's trade with the rest of the world have increased between 20 to $30 \%$ annually. There appears to be renewed commitment and optimism among the leaders of the regional groupings.

Notwithstanding the aforementioned progress by the EAC, the arrangement is still confronted by a number of challenges. For example, Kenya, Tanzania and Uganda have dominated the affairs of the EAC. If this pattern of influence continued unabated, the possibility of attaining a federation system by the end of 2015 would be a joke. As Mills (1957) has warned, for any society to operate a federal system, no single component unit should be large enough to dictate the tone and theme of that federation. By implication, there must be an equal distribution of power in order to avoid a tyrannical intra-governmental cooperation.

Closely related to the above are that there are uneasy fear and concern that the commitment of President Yoweri Musereni of Uganda, who has been the major push for the realization of the federation system is purely motivated by his desire to become the president of the expected federal system. And if these suspicious are not well managed, the EAC may 
experience a similar scenario that bedeviled its predecessor, EACM. It should be recalled that ideological differences between Nyerere and Mubutu hastened the collapse of the EACM.

In West Africa, the sub-regional organization ECOWAS has also struggled to fulfill its objectives of transforming the region. There is no doubt that the regional grouping has in many respects contributed toward the political stability of Liberia, Sierra Leone, Guinea Bissau through military and diplomatic interventions. The organization has also succeeded in the free movement of people, goods and services between member states through the ECOWAS passport. However, a major challenge to regional integration accompanied by development is the large disparity in the economy of member states. Indeed, except Nigeria, the remaining fifteen countries of ECOWAS have weak industrial and general economic bases to benefit from an expanded market.

Intra-regional trade in ECOWAS is also worrisome. Recent findings from the World Bank, IMF and evidence within reveal that about $91 \%$ of the total reported exports from ECOWAS go to destinations outside the sub-region, while only about $9 \%$ go to destinations within. The major exporters of ECOWAS are Nigeria and Cote d'Ivoire. These two ECOWAS member states account for $70 \%$ of the region is trade to the outside world. Though Nigeria is the most dominant economy in the sub-region, only $5 \%$ of its exports go through ECOWAS (Nwokoma, 2009). Intra-regional trade that is expected to foster development is between 5 to $9 \%$.

The implication of this is that many member states would continue to see ECOWAS as a creation for Nigeria to dominate others. A fact that is also supported by the obvious reality that Nigeria is economically larger than the other entire part of the region is put together. A major result of these is that after a period of 40 years, the objectives of ECOWAS have largely remained unachieved. In many respects, ECOWAS has been more successful in conflict resolutions than regional economic integration.

Like other regions in Africa, the Southern African Development Community (SADC) spearheads regional integration in Southern Africa. The aims of the organization include promoting the collective interest and interdependence of member states, improving the living standard of the people just to mention but a few. The SADC enjoyed a major boost shortly after South Africa joined the organization in 1994. As a way of demonstrating and providing leadership, South Africa promised to reduce customs barriers and free the movement of people, goods and services. By 2000, SADC also started the implementation of the "Protocol on Trade" to increase intra-trade without much impediment.

However, not much has been recorded in the intra-trade issues, which are the panacea for development. Intra-trade in SADC is put at $13.5 \%$ and $14.3 \%$ respectively. Even under this modest success in intra-trade, the Republic of South Africa is contribution is about $8 \%$ leaving the remaining member states with $5 \%$ of the intra-trade(Lipede,2008,pp186-99). 
Despite considerable gains in health sciences, the region has the highest rate of people with HIV/AIDs disease.

COMESA, which is the largest single sub-regional body in Africa, had also been dominated by the biggest economics. Intra-trade analysis between 1985 and 1993 revealed that COMESA export trade was $\$ 460.31$ million, rising to $\$ 757.4$ million in 1991 . During this period, Kenya alone accounted for $\$ 213.15$ million of the export in 1991(News African Magazine, 2014). Zimbabwe's share for the same period was $\$ 212.90$. The imports for the same period stood at $\$ 66.57$ million for Kenya, while Zimbabwe had $\$ 50.76$ million. Burundi's export was \$6.66 million and it imported goods worth \$35.94 million from COMESA. As in 2014, South Africa is export in COMESA stood at $\$ 380.77$ million and it imported just $\$ 0.66$ million worth of goods from the bloc. Thus, only the biggest economics benefited tremendously from integration in the regions. These examples are the microcosm of regional groupings in Africa. Furthermore, the local hegemon, South Africa, still classifies some countries' nationalists of COMESA as illegal; and prevents them from entering the country.

Other problems, which have served as obstacles to regional groupings to foster development in Africa include inadequate infrastructure, undemocratic regimes, multiplicity of membership of regional grouping just to mention but a few. In fact, the infrastructural supports for regional integration in different regions in Africa are grossly inadequate and lack the capacity to promote intra-trade. For example, as a result of the inadequate transportation system, the cost of moving a vehicle from the port in Mombasa in Tanzania to Kigali in Rwanda is twice the cost of shipping a car from Malaysia to Singapore. It is also easier to connect Accra-Ghana and London or Abidjan and Paris by air than it is to connect, say Accra with neighbouring Abidjan (Kehinde, 2014). Thus, inadequate infrastructure accounts for disjointed transfer network.

Political instability is also a common development as many countries of various regions continue to grapple with the basic issues of democracy. ECOWAS has devoted most of its resources to conflict resolution by intervening in Liberia, Sierra Leone and most recently in Cote d'Ivoire instead of focusing of on its primary objectives of economic integration. Kenya exploded in 2008 with so many extra-judicial killings. In Uganda, the last election in 2011 was mired by rigging owing to logistical problems and the recently concluded presidential elections in July 2015 in Burundi has been described as one of the worst elections in Africa. Just as Zimbabwe is a source of political instability to member states of the SADC.

Overlapping membership within and between sub-regional groupings have become diversionary and a waste of resources. In some instances, it breeds unnecessary antagonism. The UEMOA has remained in an unending rivalry with ECOWAS in West Africa. The fear of Nigerian hegemonic influence made France to prop up UEMOA to counterbalance Nigeria.

Many African states' economies are still structured along the monoculture colonial pattern. As a result, most countries in the continent produced basically raw materials for which they 
did not have the industrial capacity to convert them to finished goods for export. Hence, they depended on their formal colonial masters who often exploited and dictated the price of such commodities. The development has over the years contributed in subjecting African economies to external fluctuations.

\section{Conclusion and Recommendations}

Indeed a combination of things can be done to undo the challenges of regional integration in Africa. One area we can change to promote regional integration is to fine-tune our orientation, particularly the political leaders and statesmen. And yet another is that regional groupings must look inward for an economic complementary Africa. This requires the diversification of African economy to move from the mono-cultural colonial pattern. By so doing, states will produce goods and services needed by their immediate neighbours. A situation whereby all countries within the regional groupings produced the same raw materials and goods cannot encourage the intra-regional trade needed for development.

To reward weak economies and small states in regional blocs, a fixed profit-sharing strategy should also be put in place, especially on custom tariffs so that smaller economies can benefit maximally.

The generality of the people to participate in regional integration will also help. And there is the need to deemphasize the overlapping membership of regional organizations, which has in many instances served as a major impediment to cooperation and in some instances created more divisions than solutions in Africa.

Democratization and the deepening of the democratic process and culture will help to avoid unending political instability, which has become a major hallmark of the different regions of the continent. This is critical because for regional groupings to foster development, individual states must democratize democratic ideals, which will serve as a solid foundation for the African states to achieve their lofty objectives on African integration-cum development. This will also make it possible for individual states in the regional groupings to surrender part of their political sovereignty to the supra-national body, whose decisions are greater than each member state. There must also be a deliberate effort among the member states of the regional blocs to end all intra- and inter-state conflicts, which often retard economic integration.

On the whole, there is no doubt that regional integration is desirable and necessary, coupled with the fact that globalization has stimulated regional groupings such that a third of the world's trade presently takes place within regional organizations dedicated to economic cooperation and integration. African states would benefit from regional integration by looking inward and shifting toward economic complementary among the member states within the regional blocs, deemphasize total dependence on the export of primary goods and establish essential political will to accelerate development. 


\section{References}

Adejo, A. M. (2010). Regional integration in a peripheral region: A cost-benefit analysis of Nigeria's role in ECOWAS. In Akinyeye Yomi. (Ed.), Nation-States and challenges of regional integration in West Africa. Karthala: UNESC.

Adeogun, A. B. (2013). The economic commission for Africa and African's Economic Integration: A historical analysis. Unpublished doctoral Conference Paper presented at the Department of History and Strategic Studies, University of Lagos.

Akinyeye, Y. (2008). Regional integration in Africa: Past experiences, present reality and future challenges. In Yomi Akinyeye (Ed.), That they may be one: Essays in honour of professor Anthony I. Asiwaju. Imeto: African Regional Institute, 190-196.

Assante, S. K. B. (2010). The strategies for regional integration. Accra: Frederic Ebert Foundation.

Aworawo, D. (2006). Integration, economic globalization and Africa's development: The experiences of Nigeria and Botswana. In Nigerian Journal of Policy and Development, vol 5. 23-52.

Aworawo, F. (2012). Sub-regional capacity for economic integration in Africa: A comparative analysis of ECOWAS and SADC. In Okonkwo U., \& Umeji U (Ed.). New perspectives in West African history. Enugu: Mandona University Press, 515516.

Bolariwa, J. O. (2014). History of development initiatives in Africa, 1975-2010. (Unpublished doctoral dissertation). Department of History and Strategic Studies, University of Lagos.

De Lombaerde, P., \& Van, L. L.(1994). Regional integration, poverty and social policy. In Global Social Policy, 7(3), 377-383.

Deutsch, K.W. (1973). The analysis of international relations. (3rd ed.). New Delhi: Prentice-Hall.

Falola, T. (1991). History of Nigeria: Nigeria in the twentieth century. Lagos: Longman.

Ginket, H. (2003). Integration and globalization in Africa. Mumbai: Maysoce Press.

Haas, E. B. (1968). The uniting of Europe. Stanford: Stanford University Press and Hass, 1976 The obsolescence of regional integration Theory. Berkeley: University of California.

Kehinde, M.O. (2014). African regional integration: Lessons from the European Union. In The Constitution: A Journal of Constitutional Development, 14(1), 54-81.

Lipede, A. A. (2001). South Africa and integration in Southern Africa. In That They May Be One: Essays in Honour of Professor Anthony I. Asiwaju, 6-199.

Mills, J. (1958). Representative government. New York: Liberal Arts.

Mitrany, D. (1943). A working peace system: An argument for the functional development of international organisation (Landon: Royal Institute of International Affairs. Also see Ogbeide, M. M. Regional Integration: A Theoretical Analysis. In Fundamentals of economic history (Ed.) by Olukoju, A. Lawal A., \& Faluyi, K. (2003) Lagos: First Academic Publishers, 372-375. 
News African Magazine. (2015).

Nwokoma, N. I. (2009) ECOWAS and intra-regional trade, 1975-2008. In ECOWAS: Milestones in regional integration, Joy Ogwu and Wasiru Alli (Ed.). Lagos: Nigerian Institute of International Affairs, 225-238.

Nye, J. (1968). Comparative regional integration: Concepts and measurement. In International Organisation, 22 (4), 370-384.

Okonkwo, U. (2006). NAFTA and the challenges of integration in North America. In Nigerian Journal of Policy and Development, 5, 162-163.

Osuntokun, A. (2006). The African Union and the foreign policy of African States. In R. T. Akinyele (Ed.). African Integration Images and Perspectives. Lagos: University of Lagos, 108-121. See also Agubuzu, L. O. C. 2004. From the OAU to AU: The challenges of African unity and development in the twenty-first century. Lagos: Nigerian Institute of International Affairs, 19-21.

Schmitter, P. (1970). Revised theory of regional integration. In International Organisations, XXIV (4), Winter, 176-178.

Southern African Development Community (SADC). Retrieved from http://www.Africaunion.org/root/au/recs/sadchtm 